\title{
Limited precut sphincterotomy combined with endoscopic papillary balloon dilation for common bile duct stone removal in patients with difficult biliary cannulation
}

Chung-Mou Kuo ${ }^{1,2}$, Yi-Chun Chiu' ${ }^{1,2}$, Chih-Ming Liang ${ }^{1,2}$, Lung-Sheng Lu ${ }^{1,2}$, Wei-Chen Tai ${ }^{1,2}$, Yuan-Hung Kuo ${ }^{1,2}$, Cheng-Kun Wu ${ }^{1,2}$, Seng-Kee Chuah ${ }^{1,2}$, Chi-Sin Changchien ${ }^{1,2}$ and Chung-Huang Kuo ${ }^{1,2^{*}}$

\begin{abstract}
Background: Difficult biliary cannulation in endoscopic retrograde cholangiopancreatography (ERCP) can result in failure of common bile duct (CBD) stone removal and pancreatitis. The present study aimed to report the efficacy and safety of limited precut sphincterotomy (PS) combined with endoscopic papillary balloon dilation (EPBD) for CBD stone removal in patients with difficult biliary cannulation, and the complications associated with this combined procedure.

Methods: A total of 3305 patients underwent ERCP in our hospital between October 2009 and September 2014 and 258 were diagnosed with difficult biliary cannulation. Of these 258 patients, 58 underwent limited PS combined with EPBD for CBD stone removal, and these 58 patients were included in this retrospective study.

Results: The overall success rate was $94.8 \%$ (55/58), and the success rate for single-session removal was 87 . $9 \%$ (51/58). The mean procedure time was $41 \pm 11.48 \mathrm{~min}$ (range, 20-72 min). Mechanical lithotripsy was needed in $10.3 \%(6 / 58)$ of patients. Procedure-related complications included bleeding in $3.4 \%(2 / 58)$, pancreatitis in $8.6 \%(5 / 58)$ and biliary tract infection (BTI) in $1.7 \%(1 / 58)$ of patients.

Conclusions: The therapeutic outcome of limited PS combined with EPBD for CBD stone removal in patients with difficult biliary cannulation was good with an acceptable complication rate. It could be an alternative to PS and "early" limited PS should be used for prompt identification of the bile duct. Limited PS combined with EPBD is safe and effective for CBD stone removal in patients with difficult biliary cannulation.
\end{abstract}

Keywords: Precut sphincterotomy, Endoscopic sphincterotomy, Endoscopic papillary balloon dilation, Difficult biliary cannulation, Common bile duct stones

\section{Background}

A common bile duct (CBD) stone complicated with cholangitis, obstructive jaundice, or pancreatitis is a common disease of the biliary tract. Gaining access to the CBD is the most importance step for successful therapeutic endoscopic retrograde cholangiopancreatography (ERCP) [1-7].

\footnotetext{
* Correspondence: grantkuo1107@gmail.com

1Department of Internal Medicine, Division of Hepato-Gastroenterology, Kaohsiung Chang Gung Memorial Hospital, 123 Ta Pei Road, Niao-Sung Dist. 833, Kaohsiung City, Taiwan

${ }^{2}$ Chang Gung University College of Medicine, Kaohsiung, Taiwan
}

The cannulation success rate depends on patient selection, the utilization of a specialized catheter, and the skill and experience of the endoscopist [2,7]. The overall success rate of cannulation has been reported to be 90-95\% even when performed by experts [1-5]. However, in 5-10\% of cases, the CBD remains inaccessible, necessitating precut sphincterotomy (PS) or fistulotomy (PF), percutaneous transhepatic biliary drainage (PTBD), endoscopic ultrasound (EUS)-guided drainage, or surgery [1-7]. Difficult biliary cannulation is defined as a situation in which an endoscopist, using the regular cannulation technique, fails 
to cannulate the bile duct within a certain amount of time or after a certain number of attempts $[3,6]$. Some investigators have proposed the definition of difficult biliary cannulation as (1) failed cannulation within $10 \mathrm{~min},(2)>5$ pancreatic cannulation attempts, or (3) 5-10 attempts at the papilla without a time limit [1-7]. Difficult biliary cannulation leads to prolonged papillary manipulation resulting in not only tissue edema but also repeated attempts at cannulation or contrast injection of the pancreatic duct, and these factors have been reported to cause post-ERCP pancreatitis in 4.3-11.3\% of cases $[1,3,5,6]$. Needle-knife PS is the most commonly used procedures in patients with difficult biliary cannulation, and it has been reported to have success rates of 74.5-98.2 \% [1-4, 6, 7]. However, PS is associated with post-ERCP complications such as acute pancreatitis, duodenal bleeding and perforation, and is often regarded as a risky procedure, with complication rates of $2-34 \%$ [1-7]. Some published studies have reported that sequential endoscopic papillary balloon dilation (EPBD) after endoscopic sphincterotomy (EST) is safe and effective for the management of CBD stones and could decrease the occurrence of complications, including procedure-related pancreatitis [8-13]. However, reports on the efficacy of limited PS combined with EPBD for CBD stone removal in patients with of difficult biliary cannulation are scarce.

Therefore, the present study aimed to report the efficacy and safety of limited PS combined with EPBD for CBD stone removal in patients with difficult biliary cannulation, and the complications associated with this combined procedure.

\section{Methods \\ Patients}

A total of 3305 patients underwent ERCP in our hospital between October 2009 and September 2014 and 258 were diagnosed with difficult biliary cannulation. Of these 258 patients, 58 of them had their index ERCP with successful cannulations and underwent subsequent limited PS combined with EPBD for CBD stone removal. These 58 patients were analyzed in this retrospective study. On the other hand, two hundred of these patients encountered a first unsuccessful ERCP due to difficult biliary cannulation and then decided not to have a second one (none of them had received limited precut procedure). One hundred and fifty-five of them chose to receive surgery; 42 of them were treated by percutaneous biliary drainage and 3 received supportive treatments.

The definition of difficult biliary cannulation in our study was as follows: (1) failed cannulation within 10 min (2) 5 passages or injections of the pancreatic duct, or (3) 10 attempts at the papilla without a time limit (Fig. 1a). We stopped anticoagulant administration such as aspirin for 7 days before the procedures in those who were prescribed for primary prevention. For those who received anticoagulant for secondary prevention in low cardiovascular risk patients, we stopped clopidogrel,

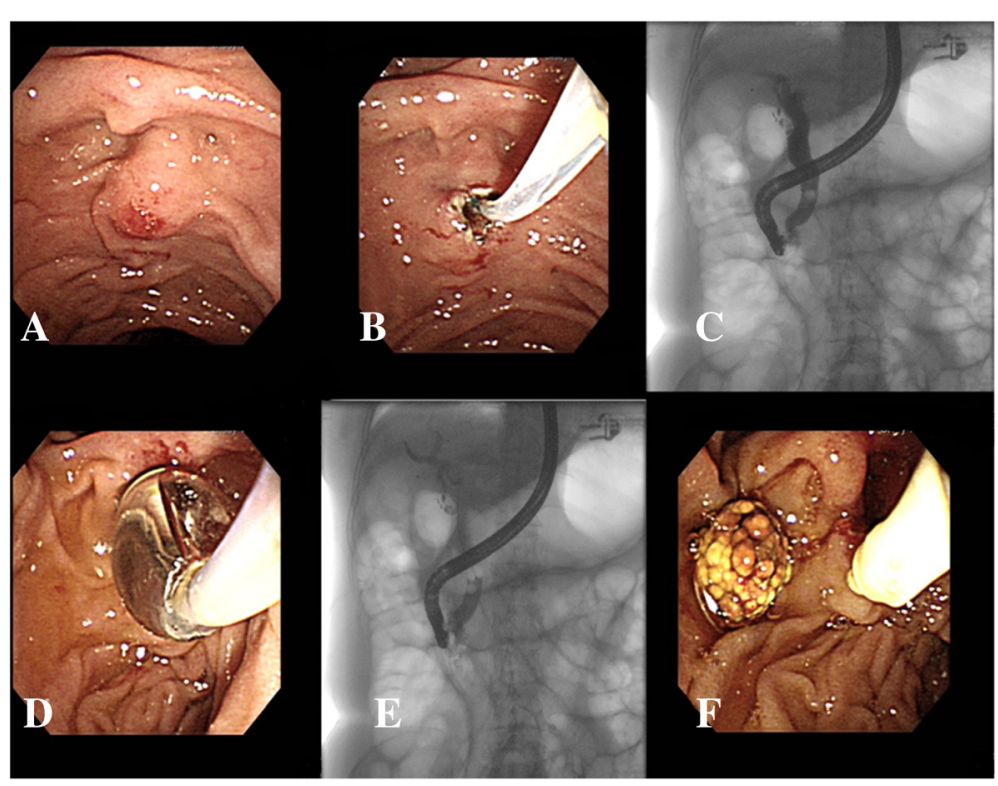

Fig. 1 a Difficult biliary cannulation was due to failure of 10 attempts at duodenal papilla; (b) Limited precut sphincterotomy was performed with the extent of cutting was less than half the length of the papillary mound; (c) Common bile duct stone was found after successful biliary cannulation; (d) Endoscopic papillary balloon dilation was performed after limited precut sphincterotomy; (e and $\mathbf{f}$ ) Common bile duct stone was extracted by retrieval balloon 
prasugrel, ticagrelor and coumadin 5 days before ERCP according to British Society of Gastroenterology and European Society of Gastrointestinal endoscopy [14, 15]. For patients with high cardiovascular risks, the procedures were postponed if possible until anticoagulant could be discontinued safely (usually $>12$ months after insertion of drug-eluting coronary stents or $>1$ month after insertion of bare metal coronary stents). However, when an emergent or semi-emergent indication like an impacted stone or jaundice in need of immediate action was encountered, cardiologists were routinely consulted and replaced by other emergent non-endoscopic bilary driange procedures. Prophylactic NSAIDs were given to all patients to reduce risk of post-ERCP pancreatitis routinely in our department.

The patients received pharyngeal anesthesia with xylocaine spray in the same manner as that for general endoscopy. Hyoscine-N-butylbromide $(20 \mathrm{mg}$ ) was administered intramuscularly before the procedure, and meperidine (30 to $50 \mathrm{mg}$ ) was administered before EPBD. ERCP was performed using a side-view endoscope (JF 260v and TJF 240; Olympus, Tokyo, Japan) after selective cannulation of the CBD with a cholangiography catheter (PR-113Q, Olympus). We preferred a needle-knife sphincterotome (KD-V441, Olympus) in all cases. Two highly experienced endoscopists [the first and second authors], with experiences of more than 3000 ERCPs procedures each, and ongoing workloads of more than 250 ERCPs procedures each annually, performed all the limited PS combined with EPBD procedures. Diathermy was applied with a blended current (20 W cut and $20 \mathrm{~W}$ coagulation) using the ESG 100 system (Olympus). The incision started from the lip of the papillary orifice (at the 11-o'clock position) and proceeded upward over the papillary mound. The extent of cutting in limited PS is less than half the length of the papillary mound (Fig. 1b). To perform EPBD after cannulation of the bile duct with limited PS (Fig. 1c), a 0.035-inch guide-wire (Zebra Exchange Guide-wire; Microvasive Boston Scientific, Watertown, MA) was inserted into the bile duct through the catheter. After the guide-wire was inserted deeply into the bile duct, the catheter was removed with the guide-wire left in place. A balloon-tipped catheter $(5.5 \mathrm{~cm}$ long and $8-20 \mathrm{~mm}$ wide; Microvasive Boston Scientific), was inserted over the guide-wire so that the balloon was extended across the papilla. The balloon was inflated to $8-20 \mathrm{~mm}$ in diameter with saline solution to dilate the papilla at progressively increasing pressures of 3 to $8 \mathrm{~atm}$ for $2 \mathrm{~min}$, according to the size of the CBD stones (Fig. 1d). After removing the dilation catheter, stones were extracted with a basket catheter or retrieval balloon (Fig. 1e, f). Endoscopic mechanical lithotripsy (EML) was used to crush stones $>15 \mathrm{~mm}$ in diameter when extraction of these stones was difficult after EPBD. When stones were not extracted completely, a biliary stent was inserted and the residual stones were removed after 3-7 days without repeating EPBD. A prophylactic pancreatic stent was not used after EPBD. Complete stone removal was defined as the absence of bile duct stones on a balloon occlusion cholangiogram.

\section{Definitions}

A procedure-related complication was defined as any adverse event related to the procedure, including pancreatitis, duodenal bleeding, perforation and biliary tract infection. Acute pancreatitis was defined as abdominal pain occurring within $24 \mathrm{~h}$ after the procedure in association with high serum amylase and lipase levels equivalent to at least 3 times the normal ranges and basal levels on the day after ERCP [2]. Bleeding was defined as any drop of over $15 \%$ in the hemoglobin level, any clinical sign of gastrointestinal bleeding (e.g., hematemesis and tarry stool), or the need for blood transfusion [2]. Perforation was defined as the leakage of contrast medium into the retroperitoneum or intraabdominal cavity during ERCP or evidence of retroperitoneal-free air on abdominal plain radiography or computer tomography $(\mathrm{CT})$ [2]. Biliary tract infection was defined as presence of fever and/or chills, abdominal pain, jaundice, and leukocytosis.

\section{Results}

This study included 58 patients (28 men and 30 women) with CBD stones who underwent limited PS combined with EPBD. The mean age of the patients was 64.02 years (range, 26-96 years). The characteristics of the patients are presented in Table 1 . The procedure findings during limited PS combined with EPBD are presented in Table 2. Complete removal of CBD stones was achieved in 55 patients $(94.8 \%)$. Of these 55 patients, 51 patients $(87.9 \%)$ required 1 session and 4 patients required 2 sessions for complete removal (Table 2). The mean size of the CBD stones was $1.11 \pm 0.40 \mathrm{~cm}$ (range, $0.4-2.0 \mathrm{~cm}$ ) and the mean diameter of CBD was $1.47 \pm 0.44 \mathrm{~cm}$ (range, 0.7 $2.6 \mathrm{~cm}$ ). Of the 58 patients, 28 patients had one stone, 14 patients had 2 stones, and 16 patients had $\geq 3$ stones. Additionally, among the 58 patients, 41 patients had distal CBD narrowing, 41 patients had jaundice, 28 patients had biliary tract infection (BTI), 19 patients had duodenal periampullary diverticulum, and 13 patients had impacted CBD stones. Removal was successful in $100 \%(19 / 19)$ of patients with stones $\leq 1 \mathrm{~cm}$ and $92.3 \%$ $(36 / 39)$ of patients with stones $>1 \mathrm{~cm}(p=0.544$, Fisher's exact test). EML was used to crush stones $>15 \mathrm{~mm}$ in diameter when extraction of these stones was difficult after EPBD in 6 patients (10.3\%). Removal failed in 3 patients because of large stones $(1.5-2.0 \mathrm{~cm})$ and CBD 
Table 1 The characteristics of 58 patients underwent limited PS combined with EPBD

\begin{tabular}{ll}
\hline Characteristics & Patient number \\
\hline Gender (M:F) & $28: 30$ \\
Mean age (range) yr & $64.02 \pm 16.37$ (26-96) \\
Age (<60 : $\geq 60: \geq 70)$ yr & $18: 40: 23$ \\
Gallstone & 31 \\
Prior cholecystectomy & 14 \\
Acute pancreatitis & 8 \\
Jaundice & 41 \\
Biliary tract infection & 28 \\
Liver cirrhosis & 7 \\
Hypertension & 22 \\
Diabetes mellitus & 11 \\
ESRD & 4 \\
CAD and heart disease & 8 \\
Hyperlipidemia & 15 \\
Malignancy & 6 \\
Stroke & 3 \\
COPD and asthma & 4 \\
\hline PS Precut sphinctomy, EPBD & \\
\hline
\end{tabular}

PS precut sphincterotomy, EPBD endoscopic papillary balloon dilation, $C A D$ coronary artery disease, COPD chronic obstructive pulmonary disease, ESRD end-stage renal disease

segmental strictures, and all the 3 patients underwent surgery for removal of the CBD stones. Among the 58 patients, 2 patients $(3.4 \%)$ had procedure-related duodenal bleeding and were successfully treated with endoscopic epinephrine injection. None of the patients with $\mathrm{CAD}$, heart disease or stroke requiring anticoagulant

Table 2 Procedure findings during limited PS combined with EPBD

\begin{tabular}{ll}
\hline Procedure findings & Number or size \\
\hline Complete bile duct stone clearance & 55 \\
$\begin{array}{l}\text { Number of sessions required to complete } \\
\text { bile duct stone clearance }(1: 2)\end{array}$ & $51: 4$ \\
Successful removal of CBD stone & $19: 36$ \\
$(\leq 1 \mathrm{~cm}:>1 \mathrm{~cm})$ & \\
Mean stone size (range) & $1.11 \pm 0.40(0.4-2.0) \mathrm{cm}$ \\
Stones size ( $\leq 1 \mathrm{~cm}:>1 \mathrm{~cm})$ & $19: 39$ \\
Stone number (1:2: $\geq 3)$ & $28: 14: 16$ \\
Mean CBD diameter (range) & $1.47 \pm 0.44(0.7-2.6) \mathrm{cm}$ \\
CBD diameter ( $\leq 0.8 \mathrm{~cm}:>0.8 \mathrm{~cm})$ & $4: 54$ \\
Periampullary diverticulum & 19 \\
Distal CBD narrowing & 41 \\
Impacted CBD stone & 13 \\
Mechanical lithotripsy & 6 \\
Procedure time & $41 \pm 11.48(20-72) \mathrm{min}$
\end{tabular}

$P S$ precut sphincterotomy, EPBD endoscopic papillary balloon dilation, $C B D$ common bile duct treatment; cirrhosis; or end-stage renal disease (ESRD) had procedure-related duodenal bleeding or perforation. Among the 58 patients, 5 patients $(8.6 \%)$ had procedure-related acute pancreatitis (mild pancreatitis). Of the 5 patients, 2 were men ( $7.1 \%$ of the 28 men) and 3 were women (10\% of the 30 women), and 2 of the 5 patients were under 60 years of age. One patient $(1.7 \%)$ had procedure-related BTI, and the pathogen was Escherichia coli. The overall complication rate was $13.7 \%(8 / 58)$. The mean follow-up period was $29.0 \pm 14.9$ months (range, 1-60 months), and no recurrence of symptomatic CBD stones was noted during the follow-up period. The mean procedure time of limited PS combined with EPBD was $41.0 \pm 11.5 \mathrm{~min}$ (range, $20-72 \mathrm{~min}$ ).

\section{Discussion}

Current study achieved a high success rate in CBD stones removal of $94.8 \%$ with a relative shorter mean procedure time needed was $41.0 \pm 11.5 \mathrm{~min}$ (range, 20$72 \mathrm{~min}$ ) in patients who underwent limited PS combined with EPBD. Difficult biliary cannulation is one major reason that influences the success rates and procedural times used to remove bile duct stones during ERCP. It is usually decided depending on the length of time, number of selective biliary cannulation attempts, or the number of unwanted pancreatic cannulations, or insertion of a guide-wire into the pancreatic duct [2]. In approximately $5-10 \%$ of patients, biliary cannulation cannot be achieved, and further complex techniques are needed. Prolonged and repeated attempts of biliary cannulation (more than 1 cannulation attempt or the cannulation time was greater than $10 \mathrm{~min}$ ) resulted in extensive injury to the papilla and lead to post-ERCP pancreatitis [16, 17].

The causes of difficult biliary cannulation are related to anatomical and physiological factors, such as a floppy papilla, small papillary orifice, cervical of the papilla, periampullary diverticulum, and surgically altered anatomy, and improper positioning of the duodenoscope $[3,4,18]$. Additionally, pathological conditions, such as stenosis of Oddi's sphincter, duodenal inflammation, ampullary and papillary neoplasms, large size or number of stones, impacted stones, bile duct strictures, and a relatively narrow distal CBD compared with the stone size can cause difficult biliary cannulation $[3,4,19]$. Distal CBD narrowing (41/58) was the major cause of difficult biliary cannulation in our study, and it may be related to chronic cholangitis. A duodenal periampullary diverticulum (19/58) and impacted CBD stone (13/58) were also common causes of difficult biliary cannulation in our study.

The solutions for overcoming difficult biliary cannulation in order to increase the success rate in CBD stones 
removal and shortening the procedure time include changing the catheter or operator, or applying a more aggressive method, keeping in mind the increased risk of complications [6]. The more aggressive methods include needle-knife PS, papillary roof excision, transpancreatic sphincterotomy, transpancreatic stenting, the double wire technique, persistence, papillectomy, and the use of a special knife [6]. If endoscopic methods fail, the transhepatic route can be used directly without an endoscopist or the rendezvous technique can be applied, depending on the cause of difficult biliary cannulation [6]. Needle-knife PS is the most commonly used technique for difficult biliary cannulation, and it has a success rate of 74.5-98.2 \% and complication rate has been reported to be $2-34 \%$ such as bleeding (2-9.5\%), pancreatitis (0.5-7.6\%) and perforation (1.4-3 \%) [1-4, 6, 7, 18, 20]. Some studies have recommended the used of needle-knife PS in the following situations: (1) stone impacting the papillary orifice, (2) significant eminence of the ampulla or dilation at the end of the CBD, (3) acute obstructive suppurative cholangitis and pancreatitis due to biliary disorder, and (4) Billroth II gastrectomy [7]. However, needle-knife PS is contraindicated for a small flat papilla, periampullary diverticulum and malignant change of the papilla, because the procedure can potentially make the cannulation approach difficult or unsafe to perform [7]. The early application of needle-knife PS for difficult biliary cannulation has been reported to be time-saving, safe, and effective, with no increase in the complication rate $[1,2,4,7]$. Limited endoscopic sphincterotomy (EST) could minimize the risk of complications that occur after complete EST such as bleeding, bile reflux and biliary tract malignancy [8]. Among the 55 patients with successful CBD stone removal, the success rate for single-session removal was $87.9 \%(51 / 58)$ while the other four needed more than once subsequent session removal of stones but were all removed eventually( $94.8 \%$ overall). The therapeutic outcome in the present study was as good as that reported previously for patients without difficult biliary cannulation who underwent EST or EPBD (79-100 \%), or combination therapy (80-100 \%) with an acceptable complication rate $(13.7 \%)$ [9-13, 18-25] with only mild procedure related pancreatitis (8.6\%) and bleeding (3.4\%).

In the present study, no difference was noted in the removal rate between CBD stones $\leq 1 \mathrm{~cm}(100 \%, 19 / 19)$ and those $>1 \mathrm{~cm}(92.3 \%, 36 / 39)(p=0.554$, Fisher's exact test). The proportion of patients who need EML to crush stones when extraction of these stones was difficult after EPBD was $10.3 \%$ in the present study. This did not differ from the proportion of patients without difficult biliary cannulation who underwent EST and EPBD combination therapy and needed EML in previous studies $(0-33 \%)$ [8-12, 23]. The procedure time for CBD stone removal was longer in the present study (mean, $41.0 \pm 11.5 \mathrm{~min}$; range, $20-72 \mathrm{~min}$ ) than in previous studies that reported patients without difficult biliary cannulation (EST: mean, $21.9 \pm 14.7 \mathrm{~min}$; range, 3-63 min and EST combined with EPBD: mean, 13.1 \pm $6.6 \mathrm{~min}$; range, 4-35 $\mathrm{min}$ ) [12]. The reason for the longer procedure time in the present study might be the extra time required owing to difficult biliary cannulation. There was no definite recurrence of symptomatic CBD stones during the follow-up period (mean, $29.0 \pm$ 14.9 months; range, 1-60 months) in our study.

The present study had some limitations. First, this was a non-randomized retrospective study. Second, the sample size was small for statistical analysis such as univariate and multivariate analysis to evaluate clinical factors associated to the outcome. A larger sample size is needed to further confirm the results of the present study.

\section{Conclusions}

The therapeutic outcome of limited PS combined with EPBD for CBD stone removal in patients with difficult biliary cannulation was good with an acceptable complication rate. It could be an alternative to PS and "early" limited PS should be used for prompt identification of the bile duct. Limited PS combined with EPBD is safe and effective for CBD stone removal in patients with difficult biliary cannulation.

\section{Abbreviations \\ CBD, common bile duct; $C T$, computer tomography; EML, endoscopic mechanical lithotripsy; EPBD, endoscopic papillary balloon dilation; ERBD, endoscopic papillary balloon dilation; ERCP, endoscopic retrograde cholangiopancreatography; ESRD, end-stage renal disease; EST, endoscopic sphincterotomy; EUS, endoscopic ultrasound; PF, precut fistulotomy; PS, precut sphincterotomy; PTBD, percutaneous transhepatic biliary drainage}

\begin{abstract}
Acknowledgements
The authors wish to thank Ms. Ching-Yi Lin for her assistance during the preparation of the manuscript.
\end{abstract}

\section{Funding}

None.

\section{Authors' contributions}

CHK participated in the design of the study, coordinated the study, performed the statistical analysis. CMK wrote the manuscript. YCC, CML, LSL, WCT, YHK, CKW, SKC, CSC participated in the design of the study and consulted on the statistical analysis. CHK and CMK consulted on design of the study and on the interpretation of results. All authors read and approved the final manuscript.

\section{Competing interest}

The authors declare that they have no competing interests.

\section{Ethics approval and consent to participate}

This retrospective chart review study was approved by both the Institutional Review Board and Ethics Committee of Chang Gung Memorial Hospital, Taiwan (IRB104-1223B). The Ethics Committee waived the requirement for informed consent, and each patient's medical records were anonymized and deidentified prior to access. All patients provided their written informed consent before endoscopic interventions. None of our patients belonged to the minors/children age groups. 
Received: 14 January 2016 Accepted: 1 July 2016

Published online: 12 July 2016

\section{References}

1. Kaffes AJ, Sriram PVJ, Rao GV, Santosh D, Reddy N. Early institution of precutting for difficult biliary cannulation: a prospective study comparing for conventional vs. a modified technique. Gastrointest Endosc. 2005;62:669-74.

2. Lim JU, Joo KR, Cha JM, Shin HP, Lee Jl, Park JJ, Jeon JW, Kim BS, Joo S. Early use of needle-knife fistulotomy is safe in situations where difficult biliary cannulation is expected. Dig Dis Sci. 2012;57:1384-90.

3. Angsuwatcharakon P, Rerknimitr R, Ridtitid W, Ponauthai $Y$, Kullavanijaya P. Success rate and cannulation time between precut sphincterotomy and double-guidewire technique in truly difficult biliary cannulation. J Gastroenterol Hepatol. 2012;27:356-61.

4. Ang TL, Kwek ABE, Lim KBL, Teo EK, Fock KM. An analysis of the efficacy and safety of a strategy of early precut for biliary access during difficult endoscopic retrograde cholangiopancreatography in a general hospital. J Dig Dis. 2010;11:306-12.

5. Testoni PA, Testoni S, Giussani A. Difficult biliary cannulation during ERCP: How to facilitate biliary access and minimize the risk of post-ERCP pancreatitis. Dig Liver Dis. 2011;43:596-603.

6. Udd M, Kylanpaa L. Halttunen. Management of difficult bile duct cannulation in ERCP. World J Gastrointest EndosC. 2010;2:97-103.

7. Zhou PH, Yao LQ, Xu MD, Zhong YS, Gao WD, He GJ, Zhang YQ, Chen WF, Qin XY. Application of needle-knife in difficult biliary cannulation for endoscopic retrograde cholangiopancreatography. Hepatobiliary Pancreat Dis Int. 2006:5:590-4.

8. Kochhar R, Dutta U, Shukla R, Nagi B, Singh K, Wig JD. Sequential endoscopic papillary balloon dilatation following limited sphincterotomy for common bile duct stones. Dig Dis Sci. 2009;54:1578-81.

9. Kim TH, Oh HJ, Lee JY, Sohn YW. Can a small endoscopic sphincterotomy plus a large-balloon dilation reduce the use of mechanical lithotripsy in patients with large bile duct stone? Surg Endosc. 2011;25:3330-7.

10. Draganov PV, Evans W, Fazel A, Forsmark CE. Large size balloon dilation of the ampulla after biliary sphincterotomy can facilitate endoscopic extraction of difficult bile duct stones. J Clin Gastroenterol. 2009;43:782-6.

11. Attasaranya S, Cheon YK, Vittal HV, Howell DA, Wakelin DE, Cunningham JT, Ajmere N, Ste Marie RW Jr, Bhattacharya K, Gupta K, Freeman ML, Sherman S, McHenry L, Watkins JL, Fogel EL, Schmidt S, Lehman GA. Large-diameter biliary orifice balloon dilation to aid in endoscopic bile duct stones removal: a multicenter series. Gastrointest Endosc. 2008;67:1046-52.

12. Itoi T, Itokawa F, Sofuni A, Kurihara T, Tsuchiya T, Ishii K, Tsuji S, Ikeuchi N, Moriyasu F. Endoscopic sphincterotomy combined with large balloon dilation can reduce the procedure time and fluoroscopy time for removal of large bile duct stones. Am J Gastroenterol. 2009;104:560-5.

13. Ersoz G, Tekesin O, Ozutemiz AO, Gunsar F. Biliary sphincterotomy plus dilation with a large balloon for bile duct stones that are difficult to extract. Gastrointest Endosc. 2003:57:156-9.

14. Veitch AM, Baglin TP, Gershlick AH, Harnden SM, Tighe R, Cairns S, British Society of Gastroenterology; British Committee for Standards in Haematology; British Cardiovascular Intervention Society. Guidelines for the management of anticoagulant and antiplatelet therapy in patients undergoing endoscopic procedures. GUT. 2008:57:1322-9.

15. Veitch AM, Vanbiervliet G, Gershlick AH, Boustiere C, Baglin TP, Smith LA Radaelli F, Knight E, Gralnek IM, Hassan C, Dumonceau JM. Endoscopy in patients on antiplatelet or anticoagulant therapy, including direct oral anticoagulants: British Society of Gastroenterology (BSG) and European Society of Gastrointestinal Endoscopy (ESGE) guidelines. Endoscopy. 2016:48:385-402.

16. Williams E, Taylor S, Fairclough P, Hamyn A, Logan RF, Martin D, Riley SA, Veitch P, Wilkinson ML, Williamson PR, Lombard M. Risk factors for complication following ERCP: results of a large-scale prospective multicenter study. Endoscopy. 2007;39:793-801.

17. Wang P, Li ZS, Liu F, Ren X, Lu NH, Fan ZN, Huang Q, Zhang X, He LP, Sun WS, Zhao Q, Shi RH, Tian ZB, Li YQ, Li W, Zhi FC. Risk factors for ERCP-related complications: a prospective multicenter study. Am J Gastroenterol. 2009;104:31-40

18. Horiuchi A, Nakayama Y, Kajiyama M, Tanaka N. Effect of precut sphincterotomy on biliary cannulation based on the characteristics of the major duodenal papilla. Clin Gastroenterol Hepatol. 2007:5:1113-8.
19. Carr-Locke DL. Difficult bile-duct stones: cut, dilate, or both? Gastrointest Endosc. 2008;67:1053-5.

20. Deng DH, Zuo HM, Wang JF, Gu ZE, Chen H, Luo Y, Chen M, Huang WN, Wang L, Lu W. New precut sphincterotomy for endoscopic retrograde colangiopancreatography in difficult biliary duct cannulation. World J Gastroenterol. 2007;13:4385-90.

21. Kuo CM, Chiu YC, Changchien CS, Tai WC, Chuah SK, Hu TH, Kuo YH, Kuo CH. Endoscopic papillary balloon dilation for removal of bile duct stones: evaluation of outcomes and complications in 298 patients. J Clin Gastroenterol. 2012;46: 860-4.

22. Kim HG, Cheon YK, Cho YD, Moon JH, do Park H, Lee TH, Choi HJ, Park SH, Lee JS, Lee MS. Small sphincterotomy combined with endoscopic papillary large balloon dilation versus sphincterotomy. World J Gastroenterol. 2009;15: 4298-304.

23. Disario JA, Freeman ML, Bjorkman DJ, Macmathuna P, Petersen BT, Jaffe PE, Morales TG, Hixson L, Sherman S, Lehman GA, Jamal MM, Al-Kawas FH, Khandelwal M, Moore JP, Derfus GA, Jamidar PA, Ramirez FC, Ryan ME, Woods KL, Carr-Locke DL, Alder SC. Endoscopic balloon dilation compared with sphincterotomy for extraction of bile duct stones. Gastroenterology. 2004;127:1291-9.

24. Fujita N, Maguchi H, Komatsu Y, Yasuda I, Hasebe O, Igarashi Y, Murakami A, Mukai H, Fujii T, Yamao K, Maeshiro K; JESED Study Group. Endoscopic sphincterotomy and endoscopic papillary balloon dilatation for bile duct stones: a prospective randomized controlled multicenter trail. Gastrointest Endosc. 2003;57:151-5

25. Chung JW, Chung JB. Endoscopic papillary balloon dilation for removal of choledocholithiasis: indications, advantages, complications, and long-term follow-up results. Gut liver. 2011;5:1-14.

\section{Submit your next manuscript to BioMed Central and we will help you at every step:}

- We accept pre-submission inquiries

- Our selector tool helps you to find the most relevant journal

- We provide round the clock customer support

- Convenient online submission

- Thorough peer review

- Inclusion in PubMed and all major indexing services

- Maximum visibility for your research

Submit your manuscript at www.biomedcentral.com/submit

) Biomed Central 